\title{
Kesenjangan Sosial dalam Novel Oliver Twist dan Nobody's Boy: Kajian Intertekstual
}

\author{
Social Discrepancy in "Oliver Twist" and "Nobody's Boy" Novel: Intertextual Study
}

\author{
Ahmad Abdullah Rosyid \\ Magister Kajian Sastra dan Budaya \\ Universitas Airlangga \\ Correspondence email: rossie.pqr@gmail.com
}

Received: 17 Juni 2020 Revised: 7 Agustus 2020 Accepted: 9 Oktober 2020

\begin{abstract}
This research uses a novel from two different countries, namely England and France, entitled Oliver Twist by Charles Dickens and Nobody's Boy by Hector Malot. Even though they were written in different countries and periods, both novels seem to be related to one another. This research utilizes the theory of intertextuality as a reference for understanding the relationship between the two novels. The social conflict theory from Karl Marx is also used to support the analysis. The method used is descriptive qualitative data sources from the two selected novels. Data collection techniques are based on things related to social conflict relationships in the novel, data collected in the form of words, phrases, and sentences from dialogue and narration. Then, data validation is done by selecting the most dominant data for intertextual analysis. Data analysis is then done by comparing the two texts as the relationship of hipogram and transformation. The results obtained are a link between the two novels in the form of interrelation between the structure of the story, which includes the background, characters and characterizations, and social conflict in the form of social disparity between the bourgeois and proletarian classes. The text of Nobody's Boy is a transformation from Oliver Twist, which gives a description and emphasis on social inequalities that occur even in years that differ greatly between the two so that from these results, it can be concluded that the two novels have an intertextual relationship in terms of influence.
\end{abstract}

Keywords: intertext, Oliver Twist, Nobody's Boy, the social discrepancy

\begin{abstract}
Abstrak: Penelitian ini menggunakan novel dari dua negara yang berbeda, yakni Inggris dan Perancis yang berjudul Oliver Twist karya Charles Dickens dan Nobody's Boy karya Hector Malot. Meskipun ditulis di negara serta masa yang berbeda, namun kedua novel terlihat saling memiliki keterkaitan satu sama lain. Penelitian ini memanfaatkan teori intertekstualitas sebagai acuan pemahaman hubungan antara kedua novel, teori konflik sosial dari Karl Marx juga dimanfaatkan untuk mendukung analisis. Metode yang digunakan adalah deskriptif kualitatif dengan sumber data dari kedua novel terpilih. teknik pengumpulan data dilakukan berdasarkan hal-hal terkait hubungan konflik sosial yang terdapat dalam novel, data yang dikumpulkan berupa kata, frasa, dan juga kalimat dari dialog maupun narasi, kemudian dilakukan validasi data dengan memilih data yang paling dominan untuk analisis intertekstual. Setelah itu, dilakukan analisis data dengan membandingkan kedua teks sebagai hubungan hipogram dan transformasi. Hasil yang diperoleh adalah bahwa adanya keterkaitan antara kedua novel berupa keterkaitan struktur cerita yang meliputi latar belakang, tokoh dan penokohan, serta konflik sosial berupa kesenjangan sosial antara kelas borjuis dan proletar. Teks Nobody's Boy merupakan transformasi dari Oliver Twist yang memberikan penggambaran dan penekanan terhadap kesenjangan sosial yang terjadi bahkan pada tahun yang berbeda jauh antara keduanya, sehingga dari hasil tersebut dapat ditarik kesimpulan bahwa kedua novel memiliki hubungan intertekstual secara keterpengaruhan.
\end{abstract}

Kata Kunci: interteks, Oliver Twist, Nobody's Boy, kesenjangan sosial

To cite this article:

Rosyid, A. A. (2021). Kesenjangan Sosial dalam Novel Oliver Twist dan Nobody's Boy: Kajian Intertekstual.

Diglosia: Jurnal Kajian Bahasa, Sastra, dan Pengajarannya, 4(1), 49-64. https://doi.org/10.30872/diglosia.v4i1.86 


\section{A. PENDAHULUAN}

Karya sastra diciptakan bukan dari sesuatu yang kosong. Seseorang menciptakan karya sastra dengan menampilkan permasalahan sosial yang muncul dalam kenyataan sosial, sehingga karya sastra tidak dapat dilepaskan dari faktorfaktor sosial budaya yang ada dalam suatu komunitas sosial (Damono, 2013, hal. 3). Dalam sebuah cerita tersirat nilai moral sosial yang dapat dijadikan sebagai pendidikan budi pekerti. Oleh karena itulah, cerita dapat dijadikan sarana atau media transformasi nilai-nilai kebaikan yang efektif. Keteladanan moral dalam cerita terepresentasi dari hubungan antara manusia dengan Tuhan, antara manusia dengan alam semesta, antara manusia dengan manusia lain sebagai individu, antara manusia dengan masyarakat sosialnya, dan antara manusia dengan dirinya sendiri (Nurgiyantoro, 2012, hal. 324). Dalam tulisan ini, peneliti membahas perbandingan kesenjangan sosial antar dua karya sastra, yakni Oliver Twist oleh Charles Dickens dan Nobody's Boy oleh Hector Mallot.

Charles Dickens, dengan nama lengkap Charles John Huffam Dickens merupakan seorang sastrawan terbesar pada era Victorian. Sebagai seorang sastrawan terkemuka, ia berhasil menciptakan karya-karya luar biasa yang begitu mengesankan, salah satunya adalah Oliver Twist (1839). Oliver Twist (selanjutnya disingkat OT) masih banyak dinikmati oleh para pembaca bahkan para penulis hingga sekarang. Berkisah tentang seorang anak laki-laki berusia sembilan tahun yang dirawat di panti asuhan, Oliver merupakan karakter yang digambarkan berani menanggung resiko yang besar dengan meminta jatah makanan tambahan karena jatah yang didapat sangatlah sedikit. Lalu diangkatlah Oliver menjadi anak angkat keluarga Sowerberry, namun penderitaannya bukan semakin berkurang, justru semakin bertambah. Dia pun memilih untuk kabur dan pergi ke London yang kemudian banyak sekali rintangan yang dihadapi Oliver yang diceritakan secara detail dalam novel tersebut.

Sedangkan Nobody's Boy (selanjutnya disingkat NB) (Prancis: Sans Famille yang berarti sebatang kara) yang terbit pada tahun 1878, juga bercerita tentang seorang anak berusia delapan tahun bernama Remi yang menjalani perjalanan yang panjang sebagai seorang musisi jalanan. Berawal dari ayahnya yang menjual dirinya pada seorang musisi bernama Signor Vitalis, Remi tumbuh dan belajar memainkan alatalat musik bersama dengan tiga ekor anjing dan seekor monyet milik Signor. Tentu saja bukanlah hal yang mudah hidup sebagai pemusik jalanan berkelana hingga menyusuri berbagai negara. NB ditulis oleh Hector Malot, seorang komposer yang juga merupakan seorang novelis asal Prancis. Tak mengherankan beberapa karya sastra yang ditulis olehnya selalu terkait dengan dunia musik.

Alasan dipilihnya dua novel tersebut adalah karena terdapatnya beberapa kesamaan terutama dalam segi kesenjangan sosial yang dialami tokoh utama yang menjadikan kedua novel tersebut saling terkait satu sama lain. Kedua novel tersebut sudah ada dalam edisi terjemahan Bahasa Indonesia dan menariknya lagi, kedua novel tersebut telah diadaptasi menjadi sebuah film dengan judul yang sama dengan novelnya. OT rilis pada tahun 2005, sedangkan NB tahun 2018 yang masih tergolong film baru. Kedua novel tersebut memiliki sudut pandang yang sama dan dipenuhi dengan nilai-nilai sosial mengenai kerasnya kehidupan sebagai seorang anak yang tidak memiliki keluarga. Selain itu, kedua tokoh utama dalam novel tersebut samasama digambarkan sebagai sosok anak kecil yang pemberani dan kuat menghadapi 
beratnya hidup. Selain itu, kajian sastra bandingan memang sudah banyak diterapkan, namun penulis masih belum menemukan kajian sastra bandingan yang terkait dengan kedua novel tersebut.

Salah satu referensi dari penelitian ini yang berkaitan dengan interteks adalah kajian yang dilakukan oleh Saraswati (2012) berjudul "Aspek Religiositas dalam Dua Novel Ericemmanuel Schmitt: Monsieur Ibrahim and the Flowers of the Koran dan Oscar and the Lady in Pink". Dalam penelitiannya tersebut, dia mencari unsur yang ada dalam dua novel karya Ericemmanuel dari segi religiusitas yang terkandung dalam kedua novel tersebut. Penelitian yang lainnya dilakukan oleh Rizkiana (2017) yang membahas nilai pendidikan yang terdapat dalam novel Edensor dan $5 C M$ dengan menggunakan kajian intertekstual. Selain itu, terdapat juga penelitian lain yang dilakukan oleh Kusuma (2018) dengan mengambil objek penelitian dua novel bertema calabai karya Okky Madasari dan Peppy Al-Bayqunie. Sedangkan penelitian yang berkaitan dengan objek penelitian ini adalah penelitian yang dilakukan oleh Persulessy (2018) yang membahas nilai-nilai sosial dalam novel Oliver Twist. Penelitian tersebut mencoba menjabarkan nilai-nilai sosial dalam novel melalui pendekatan struktural. Hasil dari penelitian tersebut adalah adanya nilai-nilai sosial dalam novel berupa nilai kasih sayang yang berupa cinta, pengabdian, keperdulian, tolong menolong, kekeluargaan, serta loyalitas.

Penelitian berikutnya yang berkaitan dengan objek kedua, yaitu novel Nobody's Boy juga telah dilakukan oleh Lestari S. (2016) dalam skripsinya yang berjudul "Strategi Bertahan dalam Novel Sans Famille Karya Hector Malot". Penelitian tersebut membahas mengenai bentuk-bentuk strategi bertahan dan peran habitus, serta arena dan modal yang terdapat dalam novel. Dengan menggunakan teori Pierre Bourdieu mengenai habitus, arena dan modal, penelitian tersebut sampai pada kesimpulan bahwa strategi bertahan yang banyak terdapat dalam novel merupakan strategi bertahan yang menggunakan modal budaya dan modal simbolik. Modalmodal itulah yang kemudian menjadi solusi untuk bertahan dalam suatu arena tertentu sehingga tokoh-tokoh dalam novel dapat merealisasikan tujuan hidupnya. Selain itu, Nanda juga menjabarkan tentang pentingnya masing-masing habitus dalam strategi bertahan di novel karya Hector Malot tersebut. Tentu saja dari penelitian-penelitian tersebut, penelitian ini hadir diharapkan dapat memberikan kontribusi dan juga mampu mengisi ruang yang tersedia dalam ruang lingkup penelitian. Pada penelitian ini, pembahasan utama adalah penjabaran mengenai aspek sosial yang tergambarkan dalam novel sesuai dengan konteks waktu yang melatar belakangi kedua novel OT dan NB.

Penelitian ini menganalisis lebih dalam mengenai pengalaman-pengalaman yang dilalui oleh Oliver dan Remi dalam menjalani kehidupan mereka dengan menggunakan teori intertekstual. Penggunaan teori tersebut dianggap sesuai karena terdapat hubungan dan kesamaan serta perbedaan antara kedua novel OT dan NB yang membuat kedua novel tersebut identik. Permasalahan yang ingin dikaji adalah apakah kedua novel tersebut menunjukkan adanya unsur keterkaitan (intertekstual) satu sama lain.

Intertekstual merupakan kata yang berasal dari akar kata inter dan teks. Inter berarti antara, di dalam, atau yang berada dalam hubungan. Sedangkan teks berasal dari bahasa Latin (textus) yang berarti susunan atau jalinan. Dengan ini intertekstual dapat bermakna hubungan atau jalinan antara satu teks dengan teks yang lain (Ratna, 2005). Definisi intertekstual merupakan teknik pengolahan dua objek yang 
didasarkan pada asumsi terjadinya keterkaitan atau pengaruh. Landasan asumsinya adalah tidak ada sebuah karya sastra yang benar-benar asli tanpa terlepas dari keterkaitan antara karya-karya sastra yang lainnya (Rohman, 2012, hal. 84-85). Setiap karya sastra yang lahir dapat dipastikan mempunyai hubungan dari karyakarya lainnya. Hubungan tersebut dapat dikaji dalam sastra bandingan. Bentuk kajiannya dapat berupa tema, struktur, aliran, serta ideologi.

Lebih lanjut lagi, Rohman (2012) menjelaskan tentang pembagian hubungan tersebut menjadi dua; pertama, hubungan pengaruh atau influence. Jenis hubungan ini adalah sebuah asumsi mengenai adanya karya sastra yang dapat memberi keterkaitan sebab-akibat kepada karya-karya yang lahir setelahnya. Tak bisa dipungkiri pula bahwa karya sastra sebagai hasil dari olah kreatif memanglah memberikan pengaruh-pengaruh di dalamnya. Hubungan yang diberikan dapat ditinjau dari segi struktur cerita, frasa yang digunakan, kalimat, bahkan tema besar yang terdapat dalam karya sastra.

Jenis hubungan yang kedua yakni hubungan kebetulan atau immanence. Pada hubungan ini dua karya sastra tertentu memang tidak memiliki keterkaitan satu sama lain, namun membahas hal yang sama persis. Hal tersebut bisa dikatakan sebagai suatu kebetulan karena alam sadar manusia bisa saja terhubung satu sama lain melalui fenomena-fenomena yang sedang terjadi. Dengan demikian, jika satu karya sastra memiliki unsur-unsur kesamaan, kemiripan dan seterusnya, tentu saja tidak dapat serta merta dikatakan bahwa karya yang satu dipengaruhi (influenced) oleh karya lainnya. Secara transformatif, pengaruh itu bukan sesuatu yang tidak mungkin terjadi. Dalam kenyataannya, memang sering kali ditemukan adanya penggalanpenggalan plot yang memiliki unsur-unsur kemiripan, pengaruh kuat dan bahkan kesamaan, Dunia globalisasi termasuk salah satu ruang terjadinya pengaruh itu.

Dalam proses pengkajian interteks, terdapat konsep yang memegang peranan penting, yakni hipogram. Riffaterre (1978, hal. 5) menjelaskan mengenai hipogram, yaitu sebuah kalimat tunggal atau serangkaian kalimat yang terbuat dari klise, berupa kutipan dari teks yang lain atau sistem yang deskriptif. Selain hipogram juga terdapat istilah transformasi. Mengenai hipogram dan transformasi karya sastra dapat dikaji menggunakan studi interteks. Pendekatan intertekstual merupakan pendekatan telaah sastra yang mengaitkan suatu teks sastra dengan teks sastra sebelumnya. Kristeva mengatakan bahwa setiap teks terwujud sebagai mosaik kutipan-kutipan, setiap teks merupakan peresapan, dan transformasi teks-teks lain (Wicaksono, 2014). Oleh karenanya, kemampuan yang sebaiknya dimiliki dalam hal interteks adalah kemampuan penguasaan pembaca atas berbagai sistem deskriptif. Selain itu, Faruk (1996, hal. 25) menjabarkan dua macam hipogram dari Riffaterre dengan sebutan hipogram yang bersifat potensial sebagai bentuk awal, sedangkan hipogram yang bersifat aktual sebagai bentuk kedua. Sehingga dapat dikatakan bahwa hipogram tersebut merupakan bentuk klise atau berupa kutipan-kutipan dari teks yang lahir sebelumnya.

\section{B. METODE}

Metode yang digunakan dalam penelitian ini adalah metode deskriptif. Data dianalisis dengan menggunakan pendekatan kualitatif yang lebih ditekankan pada teknik analisis isi. Krippendorf (1994, hal. 15) menyatakan bahwa analisis isi merupakan suatu teknik untuk membuat inferensi melalui data yang sahih dengan 
memperhatikan konteksnya. Pendekatan yang digunakan untuk menganalisis kedua novel tersebut adalah pendekatan struktural dan kajian bandingan. Dalam menelaah kedua novel tersebut, prosedur penelitian dilakukan dengan langkah-langkah sebagai berikut. Pertama, dengan melakukan studi pendahuluan, yakni studi literatur mengenai kajian interteks dan konflik sosial. Studi literatur dilakukan dengan cara melakukan telaah terhadap hasil-hasil penelitian terdahulu mengenai sastra bandingan. Hasil dari studi pendahuluan ini dijadikan sebagai dasar penentuan konsep-konsep yang akan diteliti. Kedua, mendeskripsikan persamaan dan perbedaan secara tekstual yang terdapat dalam kedua novel tersebut. Sumber data primer adalah kedua novel berjudul Oliver Twist dan Nobody's Boy. Teknik pengumpulan data dilakukan berdasarkan hal-hal terkait hubungan konflik sosial yang terdapat dalam novel, data yang dikumpulkan berupa kata, frasa, dan juga kalimat dari dialog maupun narasi, kemudian dilakukan validasi data dengan memilih data yang paling dominan memiliki hubungan antara keduanya. Setelah itu, dilakukan analisis data dengan membandingkan kedua teks sebagai hubungan hipogram dan transformasi.

\section{PEMBAHASAN}

Intertekstualitas merupakan salah satu teori yang umumnya digunakan dalam penelitian di bidang sastra. Teori ini pertama kali muncul di Eropa awal abad ke-19. Bermula dari ide yang dirumuskan oleh Sante-Beuve dalam sebuah artikelnya yang terbit tahun 1868 (Damono, 2005, hal. 14). Dalam artikel tersebut dijelaskan bahwa studi interteks telah muncul di Prancis pada awal abad ke-19. Dalam analisis ini akan dilakukan secara tiga tahap, yakni pada aspek struktural meliputi latar belakang, tokoh dan penokohan, serta konflik sosial yang terdapat dalam kedua novel. Novel Oliver Twist merupakan suatu hipogram dalam analisis ini, karena secara garis waktu, OT merupakan novel yang terbit jauh lebih dahulu dibandingkan NB, sehingga sumber yang dijadikan sebagai tolok ukur adalah yang berasal dari novel OT. Dengan demikian, novel NB merupakan transformasi dari OT. Untuk mengetahui lebih jelas mengenai hubungan hipogram dan transformasi kedua novel tersebut, analisis dilakukan sebagai berikut.

\section{a. Hubungan pada Latar Belakang dalam Novel}

Ketimpangan sosial yang ada dalam kedua novel OT dan NB tergambar begitu jelas bahkan di awal pembukaan pada masing-masing bagiannya.

"... there is one anciently common to most towns, great or small: to wit, a workhouse; and in this workhouse was born" (Dickens, 1839, hal. 2).

Terjemahan:

"... terdapat sebuah bangunan kuno yang biasa dijumpai di banyak kota, baik besar maupun kecil. Tepatnya, sebuah rumah sosial. Di rumah sosial ini lahirlah Oliver Twist kecil."

Dalam OT diceritakan bahwa Oliver lahir dan tinggal di dalam sebuah rumah yang biasa disebut workhouse atau rumah sosial. Workhouse tidak sebagus kedengarannya, karena sebenarnya istilah workhouse diartikan sebagai rumah 
penampungan para gelandangan. Workhouse sendiri adalah sebuah institusi yang didirikan untuk menampung kaum papa. Memiliki reputasi yang buruk karena penghuninya sering mendapatkan perlakuan yang tidak manusiawi. Institusi ini kemudian dihapuskan di Inggris pada tahun 1930 (Dickens, 1839, hal. 2).

Dalam NB, karakter utama Remi pun juga digambarkan dengan kondisi serupa, bahkan lebih buruk lagi.

"the village where I spent my childhood was called Chavanon; it is one of the poorest in France. Only sections of the land could be cultivated, for the great stretch of moors was covered with heather and broom. We lived in a little house down by the brook" (Malot, 1878, hal. 2).

Terjemahan:

"desa tempat aku menghabiskan masa kecilku bernama Chavanon; salah satu desa termiskin yang ada di Prancis. Hanya ada beberapa lahan yang terawat, sisanya hanya ditumbuhi semak belukar dan juga serabut sapu. Kami tinggal di dalam sebuah rumah tepat di bawah selokan."

Kedua novel tersebut masih berkaitan erat dengan kondisi sosial pada masa tersebut di mana status sosial dan perbedaan kelas masih sangat mempengaruhi kehidupan masyarakat Eropa pada waktu itu. Sistem industri yang feodal, di mana produksi industri dimonopoli oleh gilda-gilda semata, sekarang tidak lagi mencukupi kebutuhan-kebutuhan yang makin bertambah dari pasar-pasar baru. Sistem manufaktur pun menggantikannya. Tukang-tukang ahli didesak keluar oleh kelas tengah manufaktur; pembagian kerja di antara berbagai gabungan gilda hilang dengan lahirnya pembagian kerja di setiap bengkel pertukangan sendiri-sendiri.

Tiap langkah dalam perkembangan borjuasi diikuti oleh suatu kemajuan politik yang sesuai dari masing-masing kelas. Suatu kelas tertindas di bawah kekuasaan bangsawan feodal di satu tempat berupa republik-kota yang merdeka (seperti di Italia dan Jerman), di lain tempat berupa, 'pangkat ketiga' Wajib-pajak dalam monarki (seperti di Perancis). Sesudah itu, dalam masa manufaktur yang sebenarnya, dengan mengabdi pada monarki setengah-feodal atau absolut sebagai kekuatan imbangan terhadap kaum bangsawan, dan dalam kenyataannya, batu dasar bagi monarkimonarki besar pada umumnya, maka pada akhirnya borjuasi, sejak berdirinya Industri Modern dan pasar dunia, telah merebut untuk dirinya sendiri segenap kekuasaan politik di dalam Negara konstitusional modern. Badan eksekutif negara modern hanyalah merupakan sebuah komite untuk mengatur urusan-urusan bersama dari seluruh borjuasi.

Baik OT maupun NB situasi kemiskinan digambarkan sangat jelas, dimana kedua tokoh utama dalam novel tersebut bukan termasuk golongan masyarakat yang borjuis melainkan proletar. Terlihat dalam keadaan lingkungan tempat mereka lahir dan menjalani kehidupannya.

He might have been the child of a nobleman or a beggar; it would have been hard for the haughtiest stranger to have assigned him his proper station in society. But now that he was enveloped in the old calico robes which had grown yellow in the same service, he was badged and ticketed, and fell into his place at once- a parish child - the orphan of a 
workhouse - the humble, half-starved drudge-to be cuffed and buffeted through the world - despised by all, and pitied by none (Dickens, 1839, hal. 6).

Terjemahan:

Dia bisa menjadi anak siapa saja, bangsawan ataupun pengemis. Akan sulit bagi orang asing yang paling sok tahu sekalipun untuk menentukan statusnya yang pantas dalam masyarakat. Namun, setelah dibalut dengan jubah katun tua yang sudah menguning karena dimakan usia, dia pun menempati posisinya seketika, anak tanggungan desa, yatim piatu dari sebuah rumah sosial, kuli hina yang setengah kelaparan, untuk dibelenggu serta dilempar dunia ke sana kemari, dibenci semua orang, dan tak ada yang mengasihani.

Bahkan seorang bayi pun telah ditentukan status sosial mereka kelak karena pakaian yang mereka kenakan. Padahal bayi tersebut belum mengetahui apapun, akan jadi apa mereka kelak, dan mereka juga tidak pernah memilih lahir dalam keluarga apa, borjuis atau proletar. Keadaan seperti ini juga terdapat dalam NB di mana anak-anak rumah sosial diperlakukan buruk karena apa yang mereka kenakan.

In the village there were two children from the Home. They were called "workhouse children." They had a metal plaque hung round their necks with a number on it. They were badly dressed, and so dirty! All the other children made fun of them and threw stones at them (Malot, 1878, hal. 20).

Terjemahan:

Di desa ada dua anak dari 'Rumah'. Mereka biasa dipanggil anak rumah sosial. Mereka memiliki kalung metal yang menggantung di leher mereka dengan angka di atasnya. Mereka mengenakan pakaian yang buruk, dan kotor sekali! Semua anak-anak lain memperolok mereka dan melemparinya dengan batu.

\section{b. Hubungan Tokoh dan Penokohan dalam Novel}

Meskipun Oliver merupakan tokoh utama dalam novel, namun ia sama sekali tak pernah menguatkan dengan sendiri karakter yang dimilikinya. Oliver merupakan tokoh protagonis yang benar-benar pasif di mana keseluruhan karakter yang dimunculkan merupakan gambaran-gambaran yang diberikan tokoh lain kepadanya pada awal cerita, namun setelah ia memutuskan untuk keluar dari keluarga Sowerberry dan bergabung dengan musisi jalanan, karakternya menjadi kuat dengan sendirinya. Sebelum membahas mengenai penokohan, alangkah baiknya agar membahas mengenai tokoh Oliver Twist terlebih dahulu. Dalam beberapa kutipan, Oliver digambarkan sebagai anak yang benar-benar polos serta lugu. Perhatikan kutipan berikut.

One young gentleman was very anxious to hang up his cap for him; and another was so obliging as to put his hands in his pockets, in order that, as he was very tired, he might not have the trouble of emptying them, himself, when he went to bed (Dickens, 1839, hal. 91). 
Terjemahan:

Seorang pria muda sangat ingin gantung topinya untuknya; dan yang lain sangat bergerilya menaruh tangannya di sakunya, agar, karena dia sangat lelah, dia mungkin tidak sempat mengosongkan saku tersebut, sendiri, ketika dia pergi tidur.

Dalam kutipan tersebut, Oliver baru saja tiba di kediaman Fagin dan seorang pria menyambutnya dengan ramah. Namun pria tersebut tidaklah benar-benar ramah dalam artian yang sebenarnya karena ternyata ia berniat merogoh saku milik Oliver agar dapat mengambil barang yang ada di dalamnya, jika ada yang bernilai. Oliver bersikap begitu polos dengan perlakuan yang diberikan pria tersebut. Ia sama sekali tak mengetahui niat pria ketika ia merogoh saku miliknya. Oliver baru menyadari ketika ia melihat Dodger dan Charley mengambil dari saku tuan Brownlow. Dalam pandangan Oliver, pria tersebut tidaklah dianggapnya sebagai pencuri, namun tetaplah pria yang baik karena ia telah bersikap begitu sopan terhadapnya.

Akibat dari kepolosannya tersebut, Oliver Twist pun mendapatkan sebuah julukan, yang diperoleh bersamaan dengan kehadiran Fang. Pada saat Oliver terpergok oleh polisi, polisi yang membawanya bahkan tak acuh dengan menanyakan siapa namanya. Ia hanya menjulukinya sebagai Tiang Gantungan Muda. Julukan tersebut diberikan karena Oliver memiliki badang yang kurus jangkung seperti tiang gantungan. Di bagian yang sama pula, pada saat Fang menanyakan siapa nama Oliver, lagi-lagi polisi dengan seenaknya memberikan julukan yang lain, karena Oliver begitu lemah sehingga tak mampu menjawab pertanyaan Fang, sehingga polisi yang lain memberinya julukan Tom White.

Oliver tried to reply but his tongue failed him. He was deadly pale; and the whole place seemed turning round and round.

'What's your name, you hardened scoundrel?' demanded Mr. Fang. 'Officer, what's his name?'

This was addressed to a bluff old fellow, in a striped waistcoat, who was standing by the bar. He bent over Oliver, and repeated the inquiry; but finding him really incapable of understanding the question; and knowing that his not replying would only infuriate the magistrate the more, and add to the severity of his sentence; he hazarded a guess.

'He says his name's Tom White, your worship,' said the kind-hearted thief-taker (Dickens, 1839, hal. 117).

Terjemahan:

Oliver mencoba menjawab tetapi lidahnya gagal. Dia makin pucat; dan seluruh tempat tampak terbalik dan berputar.

'Siapa namamu, kamu bajingan yang keras? 'Tuntut Tuan Fang. 'Petugas, siapa namanya?'

Ia bertanya kepada seorang lelaki tua gertak, dalam garis-garis rompi, yang berdiri di dekat bar. Dia membungkuk pada Oliver, dan mengulangi pertanyaannya; tetapi ia sadar bahwa Oliver benar-benar tidak mampu untuk memahami pertanyaan; sedangkan mengatakan bahwa ia tak mau membalas 
hanya akan membuat hakim semakin marah, dan menambah beratnya hukumannya; dia menebak-nebak.

"Dia menyebut namanya Tom White, ibadatmu," kata polisi tersebut.

Julukan tersebut sekilas hanya sesuatu yang spontan diucapkan oleh polisi tersebut, namun Dickens bukan berarti memberikan julukan tersebut tanpa makna. Tom merupakan suatu nama yang sangat umum yang dimiliki oleh laki-laki di masa tersebut, namun julukan Tom juga memiliki implikasi yang lain. Drama yang sangat populer tentang penjahat dan dunia bawah London selama periode itu disebut Tom and Jerry (bukan tentang kartun kucing dan tikus). Jadi nama Tom dapat memiliki implikasi kriminal, bahkan jika seseorang tidak bermaksud demikian. Lalu nama White, bertolak pada sifat dasar yang dimiliki Oliver sendiri, yang benar-benar lugu serta polos. Seolah Oliver merupakan kertas putih yang kosong, sehingga ia dapat dijadikan apa pun yang mereka inginkan, tergantung siapa yang akan menuliskan pada kertas tersebut. Demikianlah karakter yang dimiliki oleh tokoh Oliver Twist dalam novel.

Sedikit berbeda dengan karakter yang dimiliki Oliver, Remi dalam NB memiliki karakter yang lebih mencolok, kuat dan cerdas. Hal tersebut terdapat dalam kutipan dialognya bersama dengan Ibu Barberin seperti berikut.

"Oh," I said, going up to her, "flour?"

"Why, yes," she said, smiling, "it's flour, my little Remi, beautiful flour. See what lovely flakes it makes." Just because I was so anxious to know what the flour was for I did not dare ask. And besides I did not want her to know that I remembered that it was Shrove Tuesday for fear she might feel unhappy.

"What does one make with flour?" she asked, smiling at me.

"Bread."

"What else?"

"Pap."

"And what else?"

"Why, I don't know."

"Yes, you know, only as you are a good little boy, you don't dare say. You know that today is Pancake day, and because you think we haven't any butter and milk you don't dare speak. Isn't that so, eh?

"Oh, Mother" (Malot, 1878, hal. 6).

Terjemahan:

"Oh," kataku, mendekatinya, "tepung?"

"Kenapa, ya," katanya, tersenyum, "itu tepung, Remi kecilku, cantik tepung. Lihat apa yang membuat serpihan indah. "

Hanya karena saya sangat ingin tahu apa tepung itu karena saya tidak berani bertanya. Dan selain itu saya tidak ingin dia tahu bahwa saya ingat ini Shrove Tuesday karena takut dia mungkin merasa tidak bahagia.

"Apa yang dibuat seseorang dengan tepung?" dia bertanya, tersenyum padaku.

"Roti."

"Apa lagi?"

"Pap."

"Lalu apa lagi?" 
"Kenapa, aku tidak tahu."

"Ya, kamu tahu, hanya karena kamu adalah anak kecil yang baik, kamu tidak berani mengatakan.

Anda tahu bahwa hari ini adalah hari Pancake, dan karena Anda pikir kami belum melakukannya

mentega dan susu yang tidak berani Anda bicarakan. Bukan begitu, eh? "Oh, Ibu."

Dalam dialog tersebut, Ibu Barberin rela mengutangkan kepada tetangga sejumlah tepung. Meskipun Remi sangat penasaran terhadap tepung tetapi ia sama sekali tak berniat untuk memintanya. Remi begitu sadar dengan kondisi ekonomi keluarganya, meskipun ia masih kecil. Selain itu, dalam dialog tersebut juga disebutkan bahwa Remi mampu menyebutkan makanan apa saja yang dapat dibuat dengan menggunakan bahan tepung. Padahal ia belum pernah mengetahui tepung sebelumnya, bisa dipastikan Ibu Barberin juga tak pernah membuatkan makanan tersebut untuknya, tetapi Remi telah mampu menyebutkan dengan benar daftar makanan yang dapat dibuat dengan menggunakan tepung. Terakhir, Remi pandai berpura-pura tidak mengetahui sesuatu, padahal Ibu Barberin sudah memancingmancingnya, tetapi ia tetap berkata tidak tahu. Ibu Barberin pun mengetahui bahwa Remi anak yang baik, bahkan ia tak berani menyebutkan hal yang paling diinginkannya. Hal itu dilakukan karena Remi mengerti kondisi keluarganya, sehingga ia tidak berani bersikap egois meskipun terhadap sesuatu yang begitu diinginkannya.

\section{c. Hubungan Konflik Sosial dalam Novel}

Borjuasi memang menundukkan desa kepada kekuasaan kota. Ia telah menciptakan kota-kota yang hebat, telah sangat menambah penduduk kota dibanding dengan penduduk desa, dan dengan demikian telah melepaskan sebagian besar penduduk dari kedunguan kehidupan desa. Sebagaimana halnya ia telah menjadikan desa bergantung kepada kota, begitu pun ia telah menjadikan negeri biadab dan setengah-biadab bergantung kepada negeri yang beradab, nasion kaum tani kepada nasion kaum borjuis, Timur kepada Barat. Sesuai dengan yang dialami Oliver, ketika dia kabur dari rumah keluarga Sowerberry, dia menuju ke London, kota yang begitu maju dengan segala teknologi yang dimiliki beserta industri besar yang melimpah ruah. Oliver mengadu nasibnya di sana hingga bertemulah dengan Dawkins, dimana dia berharap banyak terhadap London seperti apa yang sudah banyak orang perbincangkan semasa dalam penampungan

London!- that great place!-nobody-not even Mr. Bumble-could ever find him there! He had often heard the old men in the workhouse, too, say that no lad of spirit need want in London; and that there were ways of living in that vast city, which those who had been bred up in country parts had no idea of (Dickens, 1839, hal. 81).

London! Tempat besar itu! Tak seorang pun, bahkan Mr. Bumble akan menemukannya di sana! Dia sering mendengar dari pria tua di rumah sosial, mengatakan bahwa tak seorang pun pemuda dengan penuh semangat yang hidup berkekurangan di London; dan bahwa ada cara untuk hidup di kota luas 
itu, cara-cara yang sama sekali tak diketahui oleh mereka yang tumbuh di pedesaan.

Begitu pula dengan kondisi yang dialami oleh Remi, ayah angkatnya harus bekerja di kota yang sangat jauh dari desa kediamannya yang membuatnya tetap tinggal di kota dan bergantung nasib di sana.

"Poor Barberin," said the man as he dried the legs of his trousers, which were now quite stiff under the coating of mud, "he's got no luck, no luck! Some chaps would get a mint o' money out of an affair like this, but your man won't get nothing!"

"No luck!" he said again in such a sympathetic tone, which showed plainly that he for one would willingly have the life half crushed out of his body if he could get a pension. "As I tell him, he ought to sue that builder."

"A lawsuit," exclaimed Mother Barberin, "that costs a lot of money" (Malot, 1878, hal. 4).

Terjemahan:

"Barberin yang malang," kata pria tersebut seraya mengeringkan pakaiannya, yang mana dipenuhi oleh noda lumpur, "dia sama sekali tak beruntung! Beberapa lelaki akan mendapatkan uang dari kejadian ini, tetapi suamimu tak mendapatkan apa pun!"

"Pengadilan," seru Ibu Barberin, "biayanya mahal sekali."

Dalam NB, ketika Remi berusia delapan tahun, terjadilah suatu kecelakaan yang menimpa ayah angkatnya yang bekerja di Paris. Perkara tersebut ingin diajukan ke pengadilan supaya ayahnya mendapat ganti rugi uang yang cukup besar dari keputusan pengadilan, namun ibunya masih ragu untuk mengambil keputusan tersebut karena biaya pengadilan terlalu mahal bagi warga proletar sepertinya.

Di samping itu, masyarakat Proletariat melalui berbagai tingkat perkembangan. Bersamaan dengan lahirnya, mulailah perjuangannya terhadap borjuasi. Mula-mula perjuangan itu dilakukan oleh kaum buruh secara perorangan, kemudian oleh buruh dalam satu pabrik, kemudian oleh buruh dari satu macam perusahaan di satu tempat melakukan perlawanan terhadap borjuis yang merupakan orang-orang yang hanya menyudutkan mereka. Mereka tidak mengerahkan serangan-serangannya terhadap syarat-syarat produksi borjuis, tetapi terhadap perkakas-perkakas produksi itu sendiri; mereka merusakkan barang-barang impor yang menyaingi kerja mereka, mereka menghancurkan mesin-mesin, mereka membakar pabrik-pabrik, mereka mencoba mengembalikan dengan paksa kedudukan pekerja dari kaum Luddis yang telah hilang itu.

Be this as it may, however, it was his ninth birthday; and he was keeping it in the coalcellar with a select party of two other young gentleman, who, after participating with him in a sound thrashing, had been locked up for atrociously presuming to be hungry, when Mrs. Mann, the good lady of the house, was unexpectedly startled by the apparition of Mr. Bumble, the beadle, striving to undo the wicket of the garden-gate (Dickens, 1839, hal. 10). 
Terjemahan:

Bagaimanapun, di tengah segala keterbatasan, ini adalah ulang tahunnya yang kesembilan. Saat ini dia sedang merayakannya di gudang batu bara bawah tanah bersama tamu pilihan yang terdiri dari dua pemuda kecil lainnya. Mereka dikurung karena ikut protes bersama Oliver dengan berpura-pura lapar ketika Nyonya Mann, sang nyonya rumah yang baik hati, tak diduga-duga kemunculan Tuan Bumble, sekretaris desa, yang sedang berjuang membuka pintu pagar taman.

Dalam OT, Dickens mencoba mendeskripsikan bentuk perlawanan sosial dari kelas proletar melalui anak-anak yang sedang memprotes atas jatah makanan yang mereka dapatkan dari Nyonya Mann.

NB juga menyiratkan perlawanan dari proletar melalui karakter Remi. Pada saat Remi akhirnya diadopsi oleh Tuan Vitalis, Remi sangat ingin kabur dan kembali ke rumah untuk menemui Ibu Barberin yang sangat dia cintai. Walau pada akhirnya dia hanya bisa pasrah karena telah melangkah terlalu jauh dan takut akan tersesat.

Run away-I no longer thought of doing so. Where should I go? This tall old man perhaps would be a kind master after all. I had never walked so far at a stretch. All around us were barren lands and hills, not beautiful like I had thought the world would be outside of my village (Malot, 1878, hal. 44).

Kabur, Aku sudah tidak memikirkannya lagi. Ke mana aku harus pergi? Pria tua tinggi ini mungkin akan menjadi tuan yang baik. Aku tidak pernah berjalan sejauh ini. Sekeliling hanyalah tanah gersang dan perbukitan, tidak seindah bayanganku mengenai dunia luar yang jauh dari desa.

Kutipan tersebut mengindikasikan betapa kuatnya kendali yang dimiliki oleh kelas borjuis kepada kelas proletar. Seperti yang telah diungkapkan oleh Karl Marx yang mengutip dari Frans Magnis (Magnis, 1999, hal. 20) bahwa seluruh keteraturan yang dilakukan oleh kaum proletar ialah bagian dari adanya suatu paksaan dari kaum borjuis. Hal tersebut terjadi karena kelas borjuis telah berhasil memperoleh kekuasaan dari segi ekonomi maupun politik. Dari kekuasaan pada kedua bidang tersebut, mereka pun menjadikan hubungan antar manusia sebagai transaksi komersial, yakni menempatkan kedudukan para pekerja seolah tak lebih dari barang dagangan saja. Hal inilah yang membuat kaum proletar kemudian merasa dendam dan sakit hati, yang mengakibatkan mereka membuat suatu organisasi atau perkumpulan dengan tujuan untuk melawan penindasan yang dilakukan para borjuis kepada mereka. Serta sebagai bentuk dari pembelaan diri dengan upaya menciptakan kekacauan dalam masyarakat. hal tersebut sama seperti yang dilakukan Oliver Twist bersama kawan-kawannya di panti asuhan yang berusaha mengacau pada saat makan malam. Hal tersebut merupakan representasi dari protesnya rakyat proletar terhadap borjuis yang diperlakukan dengan tidak adil.

Dari hasil-hasil yang didapatkan di atas mengenai ketimpangan sosial yang sangat miris dan kejam, terdapat juga pembahasan mengenai nilai sosial yang positif yang berkaitan antara kedua novel tersebut. Pertama, yakni keterkaitan antara tokoh utama dalam kedua novel. Dapat dilihat dari data yang telah dijabarkan di atas, bahwa tokoh Oliver Twist terlahir dalam situasi yang tidak seberuntung anak-anak 
lain yang mungkin dilahirkan dari keluarga yang mapan dan terpandang. Meski begitu, ibunya begitu bahagia di saat ia melahirkan anaknya tersebut, walaupun tak lama setelah itu ia meninggal. Hal tersebut telah diungkapkan dalam penelitian yang ditulis oleh Persulessy (2018) tentang nilai cinta dan kasih sayang. Setidaknya, ibu Oliver merupakan sosok yang begitu menyayanginya, terlebih jika masih hidup. Betapa dunia yang mencoba menolak Oliver Twist, sang ibu akan tetap berada pada pihak Oliver serta akan selalu mendukungnya. Begitu juga dengan tokoh Remi dalam Nobody's Boy, yang berusaha dijual oleh tokoh Ayah kepada Signor Vitalis. Dalam kutipan yang telah dibahas di atas terdapat ungkapan bahwa Remi sangat menginginkan untuk menemui ibu Barberin untuk terakhir kalinya, namun sudah terlampau jauh. Dalam cerita, Ibu Barberin memang sama sekali tidak mendukung keputusan suaminya untuk menjual Remi hanya karena masalah ekonomi mereka yang semakin buruk. Bahkan meskipun Monsieur Barberin telah memesan istrinya agar menaruh Remi di panti asuhan, tetapi tetap tidak ia lakukan. Ini menunjukkan bahwa kedua tokoh utama dalam novel, yakni Oliver dan Remi sama-sama memiliki ibu yang begitu menyayangi mereka. Sehingga emosi yang juga terbentuk dari ibu mereka kepada kedua tokoh tersebut dapat menentukan perjalanan mereka selanjutnya.

Kedua, yakni keterkaitan stigma masyarakat luas yang sepertinya telah mendarah daging, bahwasanya hidup di kota lebih menjanjikan daripada hidup di pedesaan. Pada kutipan-kutipan yang telah disertakan di atas memang telah di bahas mengenai keterkaitan antara kedua novel mengenai tanggapan orang-orang desa tentang kehidupan di kota. Bahkan hingga saat ini pun, pandangan tersebut masih saja berlaku, khususnya di negara Indonesia. Dalam pola pikir masyarakat secara umum, kerap sekali ditemukan stigma mengenai desa yang hanya terdapat sawah serta wilayah yang tertinggal. Sawah merupakan lambang yang identik dengan desa, karena pemukiman warga tidak terlalu padat sehingga cocok sekali untuk dijadikan sebagai lahan untuk bercocok tanam. Lain halnya dengan kota, yang merupakan pusat pemukiman serta administratif dari berbagai kalangan. Sehingga stigma yang muncul dari kehidupan di kota adalah bahwa hidup di kota akan terjamin karena mudahnya akses serta perputaran bisnis. Stigma-stigma tersebut sebenarnya tak luput dari pemberian label dari orang-orang terdahulu, dan hal tersebut memberikan dampak yang begitu besar bagi pola pikir masyarakat baik dari masyarakat desa maupun kota. Stigma tersebut akan tetap terus muncul secara turun-temurun bahkan tak akan hilang dengan mudahnya dalam pikiran masyarakat. hal tersebut terjadi karena sejatinya pemikiran manusia sekarang merupakan bagian dari konstruksi pemikiran orang-orang terdahulu.

Ketiga, Pada pertengahan masa Victoria yang ditandai dengan maraknya Revolusi Industri di mana terjadi perubahan total yang dihasilkan dari perkembangan teknologi dan banyaknya penemuan baru dalam bidang ilmu pengetahuan, menyebabkan perubahan pada aspek sosial, budaya, ekonomi dan politik di masyarakat Inggris. Revolusi industri banyak memberikan aspek positif terutama dalam bidang pendidikan yang menjadi lebih maju dan meningkat, di mana masyarakat mulai banyak yang belajar menulis dan membaca, namun dibalik aspek positif ternyata terdapat tingginya kesenjangan sosial antara masyarakat kaya dan miskin. Hal ini yang memunculkan istilah borjuis dan proletar (Samekto, 1975, hal. 77). Fenomena tentang masyarakat borjuis dan proletar menarik perhatian banyak 
penulis saat itu untuk menangkap keadaan masyarakat di tengah menghadapi perubahan besar tersebut ke dalam karya sastra.

Dalam sistem produksi kapitalis dua kelas tersebut memang terjadi saling ketergantungan, namun ketergantungan itu tidaklah seimbang. Hal tersebut dikarenakan para proletar tidak akan bisa bertahan hidup jika tidak bekerja. Sedangkan bagi para borjuis, tidak akan ada masalah yang begitu besar jika nanti pabrik yang dimilikinya tidak berjalan dengan lancar. Mereka masih dapat memperoleh uang dengan menjual pabrik mereka, atau peralatan-peralatan produksi mereka. Dalam konsep kapitalis dua kelas ini, akan terlihat jelas bahwa kelas borjuis merupakan kelas yang kuat dan mendominasi, sedangkan kelas proletar adalah kelas yang lemah dan submissive. Dalam praktiknya, kedua kelas ini memang berada dalam struktur hierarki sosial. Orang-orang borjuis akan selalu melakukan eksploitasi terhadap orang-orang dari kalangan proletar dalam hal produksi. Status kepemilikan akan alat-alat produksi juga merupakan upaya dari pemisahan kelas-kelas sosial dalam masyarakat. Marx pun menjelaskan jika seluruh keteraturan yang dialami oleh masyarakat proletar merupakan akibat dari adanya suatu kendali yang dilakukan oleh para penguasa (Magnis, 1999, hal. 20).

Dari analisis yang telah dilakukan, maka dapat diketahui bahwa NB merupakan transformasi terhadap OT yang bersifat meneruskan. Hal itu karena mayoritas aspek yang terdapat dalam NB merupakan penerusan makna yang berasal dari OT, hanya dalam hal tokoh dan penokohan yang sedikit menyimpang, tetapi secara keseluruhan merupakan penerusan terhadap makna-makna dari teks yang lahir sebelumnya.

\section{PENUTUP}

Hubungan yang terdapat pada beberapa narasi, dialog, dan juga struktur dalam kedua novel OT dan NB menunjukkan adanya hubungan intertekstual secara terpengaruh antara karya Charles Dickens dengan Hector Malot tersebut. Keduanya berusaha menggambarkan kondisi kesenjangan sosial yang ada pada masa di saat kedua novel tersebut dibuat, juga terdapat istilah yang juga sama-sama disebutkan dalam kedua novel seperti workhouse yang digambarkan dalam kedua novel tersebut sebagai tempat yang tak layak untuk ditinggali dan juga anak-anak mendapatkan perlakuan yang buruk. Novel NB yang mentransformasi novel OT banyak mengambil peran di dalamnya. Dari segi latar belakang cerita, kedua novel samasama memiliki latar belakang dari sudut pandang kalangan proletar. Hal tersebut ditunjukkan dalam karakter utama yang ada dalam novel, yakni Oliver dan Remi.

Dari segi tokoh dan penokohan, NB lebih memiliki karakter utama yang kuat, sedangkan OT sebagai hipogram memiliki karakter utama yang cukup pasif dibanding NB. Dari segi konflik sosial, kedua novel sama-sama menampilkan potret perjuangan kaum proletar yang berusaha melawan penindasan atas apa yang dilakukan oleh kaum borjuis. Oleh karena itu, pada simpulan ini dapat dikatakan bahwa transformasi dalam novel NB merupakan transformasi yang bersifat meneruskan. Meskipun kedua novel mengambil latar belakang tempat dan waktu yang berbeda, namun kesenjangan sosial masih saja digambarkan jelas di kedua novel yang telah dibahas dalam artikel ini. Hal tersebut menunjukkan bahwa memang pada masa Victoria, banyak sekali kemajuan yang telah diberikan kepada masyarakat, namun karena perubahan sistem ekonomi yang menjadikan mereka 
tergolong berdasarkan status sosial mereka, yang pada akhirnya membuat yang kaya semakin kaya dan yang miskin akan terus berada dalam keterpurukan.

\section{DAFTAR PUSTAKA}

Damono, S. D. (2013). Sosiologi Sastra: Suatu Pengantar Ringkas. Jakarta: Pusat Pembinaan dan Pengembangan Bahasa, Departemen Pendidikan dan Kebudayaan.

Dickens, C. (1839). Oliver Twist. London: Richard Bentley.

Lestari S., F. N. (2016). Strategi Bertahan Dalam Novel Sans Famille Karya Hector Malot. Universitas Gadjah Mada.

Krippendorf. (1994). Analisis Isi: Pengantar Teori dan Metodologi. Jakarta: Rajawali Pers.

Kusuma, K. A. (2018). Pengakuan Calabai: Sebuah Analisis Intertekstual Novel Pasung Jiwa Karya Okky Madasari dan Novel Calabai Karya Pepi Al-Bayqunie. Jurnal Kata, 2(1). Retrieved from http://ejournal.1ldikti10.id/index.php/kata/article/view/3148

Magnis, F. (1999). Pemikiran Karl Marx "Sosialisme Utopis Keperselisihan Revolusionism." Jakarta: PT. Gramedia Pustaka Utama.

Malot, H. (1878). Nobody's Boy. New York: Cupples \& Leon Company.

Nurgiyantoro, B. (2012). Teori Pengkajian Fiksi. Yogyakarta: Gajah Mada University Press.

Ratna, N. K. (2005). Sastra dan Cultural Studies. Yogyakarta: Pustaka Pelajar.

Rizkiana, S. (2017). Kajian Intertekstual dan Nilai Pendidikan Novel Edensor Karya Andrea Hirata dan Novel 5 CM Karya Donny Dhirgantoro. Seminar Nasional Bahasa, Sastra, dan Budaya. Retrieved from https://sia.umpwr.ac.id/prosiding/index.php/bahtera/article/view/44

Rohman, S. (2012). Pengantar Metodologi Pengajaraan Sastra. Yogyakarta: Ar-Ruzz Media.

Samekto. (1975). Ikhtisar Sejarah Kesusasteraan Inggris. Jakarta: Daya Widya.

Saraswati, R. (2012). Aspek Religiositas dalam Dua Novel EricEmmanuel Schmitt: Monsieur Ibrahim and the Flowers of the Koran dan Oscar and the Lady in Pink. Jurnal Atavisme, 15(1). https://doi.org/10.24257/atavisme.v15i1.54.140-147

Persulessy, S. I (2018). Makna Nilai Nilai Sosial dalam Novel Oliver Twist Karya Charles Dickens. Lingua Rima, 7(2). http://dx.doi.org/10.31000/lgrm.v7i2.879

Wicaksono, A. (2014). Pengkajian Prosa Fiksi. Jakarta: Garudhawaca. 
